PharmacoEconomics \& Outcomes News 876, p26 - 17 Apr 2021

\title{
Primary prophylaxis with biosimilar filgrastim cost-effective approach to avoid febrile neutropenia
}

Primary prophylaxis (PP) with biosimilar filgrastim is cost effective in patients at intermediate risk for febrile neutropenia (FN) receiving chemotherapy for breast cancer, non-small-cell lung cancer (NSCLC) or non-Hodgkin lymphoma (NHL) in the US.

This is the main finding of a study that used a Markov model with a lifetime horizon to evaluate the cost effectiveness of PP versus secondary prophylaxis (SP) using a biosimilar filgrastim (specifically filgrastim-sndz) in patients at intermediate risk for FN receiving chemotherapy for breast cancer (adjuvant docetaxel), NSCLC (adjuvant carboplatin and paclitaxel) or NHL (cyclophosphamide, doxorubicin, vincristine and prednisone [R-CHOP]). ${ }^{*}$ The analysis was conducted from a US payer perspective.

Over all three cancer types, biosimilar filgrastim (using filgrastim-sndz) as PP provided an additional 0.102-0.144 life-years (LYs) and 0.065-0.130 quality-adjusted life-years (QALYs), compared with SP. The incremental costs ranged from \$US650 to \$US2463 (year 2020 values). Costs included those associated with biosimilar filgrastim, based on the average sales price of filgrastim-sndz as of July 2020, as well as filgrastim administration, and inpatient or outpatient FN management. The incremental cost-effectiveness ratios ranged from \$US5660 to \$US20 806 per FN event avoided, \$US5123 to \$31 077 per LY gained and \$US7213 to \$US35 563 per QALY gained. "Using a biosimilar filgrastim (specifically filgrastim-sndz) as PP is a cost-effective approach to avoid FN events, which reduces the need for patients to receive hospital or outpatient care. This is especially important for reducing transmission of SARS-CoV-2 among patients with cancer, who are highly susceptible to the complications of COVID-19," note the researchers.

* The study was supported by Sandoz, Inc.

Li E, et al. Primary Prophylaxis With Biosimilar Filgrastim for Patients at Intermediate Risk for Febrile Neutropenia: A Cost-Effectiveness Analysis. JCO Oncology Practice : OP2001047, Apr 2021. Available from: URL: http://doi.org/10.1200/OP.20.01047 